Jurnal ABDINUS : Jurnal Pengabdian Nusantara, 3 (1), 2019, 100-110

Available online at: http://ojs.unpkediri.ac.id/index.php/PPM

DOI: https://doi.org/10.29407/ja.v3i1.13110

\title{
Implementasi SWOT dalam Penentuan Program Pendampingkan Pemberdayaan UKM Produksi Pangan Rumah Tangga
}

\author{
Albertus Daru Dewantoro ${ }^{1 *}$, Alberth $^{2}$, Nathan Nikolaus ${ }^{3}$, Yohanes D. C. Ivan ${ }^{4}$, \\ Fransisca L. ${ }^{5}$, Fininonsi J. ${ }^{6}$, Kristoforus Mone ${ }^{7}$ \\ ${ }^{1}$ Albertus.daru@ukdc.ac.id \\ $1,2,3,4,5,6,7$ Prodi Teknik Industri \\ $1,2,3,4,5,6,7$ Fakultas Teknik \\ 1,2,3,4,5,6,7 Universitas Katolik Darma Cendika
}

Received: 0307 2019. Revised: 1707 2019. Accepted: 04092019

\begin{abstract}
The government encourages community elements to be economically independent. The encouragement and support was realized with facilities for the community to establish UKM. Through SMEs, the community is expected to be able to empower all the resources they have to achieve prosperity. SMEs in the food sector are very high growth, SME capacity development needs to be improved, and food security issues need to be addressed. Fulfillment of safe and quality food is the basic right of every human being, including food produced by the Household Food Industry. CV. Panca Boga Langgeng is our abdimas partner that produces household-scale food products, which have the desire to increase its business capacity, the obstacles faced are market share only limited to family, friends and circles around the place of business. Business owners cannot produce on a larger scale and market widely because they do not have legality. To understand the problems and potential of our partner SMEs, we use the SWOT method, the work system of the SWOT method in formulating strategic solutions is outlined in the matrix, internal and external aspects are used as the basis for determining strategies or efforts that can be achieved so that business objectives can be achieved. The results of community service activities include: the partner has a NPWP, a business permit and has received a registration number for the management of BPOM's distribution permit.
\end{abstract}

Keyword: SWOT Analysis, Community Service, Food Security, BPOM.

Abstrak: Pemerintah mendorong masyarakat untuk mampu mandiri secara ekonomi. Dorongan dan dukungan itu diwujudkan dengan fasilitas kemudahan bagi masyarakat untuk mendirikan UMKM (Usaha Mikro Kecil dan Menengah). Dengan UMKM, masyarakat diharapkan mampu memberdayakan segala sumber daya yang dimiliki untuk mencapai kesejahteraan. UMKM bidang pangan sangat tinggi pertumbuannya, pengembangan kapasitas UMKM perlu ditingkatan serta isu keamanan pangan perlu menjadi perhatian. Pemenuhan pangan yang aman dan bermutu merupakan hak asasi setiap manusia, tidak terkecuali pangan yang dihasilkan oleh Industri Rumah Tangga Pangan. CV. Panca Boga Langgeng adalah mitra abdimas kami yang memproduksi hasil pangan skala rumah tangga, yang memiliki keinginan untuk meningkatkan kapasitas usahanya, hambatan yang dialami adalah pangsa pasar hanya sebatas keluarga, teman 
dan lingkuang disekitar tempat usaha. Pemilik usaha belum berani memproduksi dalam skala yang lebih besar dan memasarkan secara luas dikarenakan belum memiliki beberapa kelengkapan legalitas yang harus dimiliki sebagai usaha industri makanan. Untuk memahami permasalahan maupun potensi dari UMKM mitra kami, kami menggunakan metode SWOT, sistem kerja metode SWOT dalam merumuskan solusi strategis dituangkan dalam matriks. Secara kualitatif, askep internal dan ekternal dijadikan dasar dalam penetapan strategi atau upaya yang dapat dilakukan, agar tujuan bisnis dapat dicapai. Hasil dari abdimas adalah mitra telah memilik NPWP, ijin Usaha dan telah mendapat nomor registrasi untuk pengurusan ijin edar BPOM.

Kata kunci : SWOT Analysis, Abdimas, Kemamanan Pangan, Ijin Edar BPOM.

\section{ANALISIS SITUASI}

Dosen dan Mahasiswa memiliki peran terhadap perubahan yang lebih signifikan dan progresif, khususnya dalam upaya mengembangkan masyarakat yang lebih sejahtera, adil dan makmur, dengan menggunakan wawasan intelektual yang disertai dengan kegiatan yang nyata. Peran dosen dan mahasiswa dari masa ke masa terus diharapkan dapat berkembang dan semakin bermutu sehingga membawa dampak yang besar bagi masyarakat, baik di bidang sosial, politik, maupun ekonomi. Salah satu darma sebagai dosen dan mahasiswa diwujudkan dalam suatu program pengabdian kepada masyarakat.

Saat ini pemerintah sedang gencar mendorong masyarakat untuk mampu mandiri secara ekonomi. Dorongan dan dukungan itu diwujudkan dengan fasilitas kemudahan bagi masyarakat untuk mendirikan UMKM (Usaha Mikro Kecil dan Menengah). Dengan UMKM, masyarakat diharapkan mampu memberdayakan segala sumber daya yang dimiliki untuk mencapai kesejahteraan. Berdasarkan permikiran di atas, maka dalam pelaksanaan abdimas kami berkomitmen akan ikut ambil bagian dalam upaya meningkatkan kesejahteraan masyarakat melalui kegiatan dengan berfokus pada pengembangan kapasitas UMKM. Mitra kami adalah salah satu UMKM yang bergerak di bidang industri makanan, yang secara khusus memproduksi bakso dan bakwan yaitu CV. Panca Boga Langgeng, industri yang memproduksi hasil pangan yang diproduksi skala rumah tangga.

Pemenuhan pangan yang aman dan bermutu merupakan hak asasi setiap manusia, tidak terkecuali pangan yang dihasilkan oleh Industri Rumah Tangga Pangan (IRTP). Undang-Undang Nomor 36 Tahun 2009 tentang Kesehatan dalam Pasal 111 ayat (1) menyatakan bahwa makanan dan minuman yang digunakan masyarakat harus didasarkan pada standar dan/atau persyaratan kesehatan. Makanan dan minuman yang tidak layak atau 


\section{Jurnal ABDINUS : Jurnal Pengabdian Nusantara, 3 (1), 2019, 100-110}

Albertus Daru Dewantoro, Alberth, Nathan Nikolaus, dkk

memenuhi ketentuan yang telah distrandarisasi, tidak memenuhi persyaratan kesehatan, dan/atau membahayakan kesehatan maka dilarang untuk diedarkan secara bebas, dan harus ditarik dari peredaran, dicabut izin edar dan dilakukan penyitaan ketentuan peraturan undangundangundangan. Dalam rangka produksi dan peredaran pangan oleh IRTP, Pasal 43 Peraturan Pemerintah Nomor 28 Tahun 2004 tentang Keamanan, Mutu dan Gizi Pangan mengamanatkan bahwa pangan olahan yang diproduksi oleh industri rumah tangga wajib memiliki Sertifikat Produksi Pangan Industri Rumah Tangga (SPP-IRT) yang diterbitkan oleh Bupati/Walikota dan Kepala Badan POM menetapkan pedoman pemberian SPP-IRT. Sementara itu, Peraturan Pemerintah Nomor 38 Tahun 2007 tentang Pembagian Urusan Pemerintahan Antara Pemerintah, Pemerintah Daerah Provinsi, dan Pemerintah Daerah Kabupaten/Kota pada Bidang Kesehatan - sub bidang Obat dan Perbekalan Kesehatan, mengamanatkan bahwa pengawasan dan registrasi makanan minuman produksi rumah tangga merupakan urusan pemerintahan yang wajib diselenggarakan oleh Pemerintah Daerah Kabupaten/Kota. Di sisi lain, Pemerintah berkewajiban meningkatkan daya saing produk pangan industri rumah tangga melalui peningkatan kesadaran dan motivasi produsen tentang pentingnya pengolahan pangan yang higienis (Departemen Kesehatan, 2009).

Di daerah Kelurahan Kapas Madya banyak rumah tangga yang menggeluti UKM bidang pangan. Untuk kesempatan abdimas ini, berdasarkan informasi pendahuluan yang diterima dari tokoh masyarakat setempat, serta mempertimbangkan kapasitas tim yang melakukan pengabdian masyarakat, maka untuk menjadi objek dan contoh pelaksanaan pendampingan masyarakat kami adalah CV. Panca Boga Langgeng.

CV. Panca Boga Langgeng hanya memproduksi sesuai pesanan saja. Pangsa pasar hanya sebatas keluarga, teman dan lingkungan disekitar tempat usaha. Pemilik usaha belum berani memproduksi dalam skala yang lebih besar dan memasarkan secara luas dikarenakan belum memiliki beberapa kelengkapan legalitas yang harus dimiliki sebagai usaha industri makanan seperti yang diuraikan pada paragraf sebelumnya. Hal itu menjadi hambatan tersendiri bagi perkembangan UMKM ini. Berikut adalah profil mitra abdimas kami secara umum:
Nama UMKM
: CV. Panca Boga Langgeng
Nama Pemilik
: Ibu Hebby
Domisili tempat usaha
: Jl. Kapas Madya $1 \mathrm{G}$ No. 75, Surabaya
Tahun berdiri
: 2016
Bidang Usaha
: Industri kecil makanan 


\section{Jurnal ABDINUS : Jurnal Pengabdian Nusantara, 3 (1), 2019, 100-110}

Albertus Daru Dewantoro, Alberth, Nathan Nikolaus, dkk

Merek dagang

\section{: Bakwan AH}

Untuk memahami permasalahan maupun potensi dari UMKM mitra kami, kami menggunakan metode SWOT, dimana melalui metode SWOT kami dapat mengetahui kekuatan, kelemahan, peluangan dan ancaman Mitra. SWOT sebuat teknik analisis yang dikembangkan oleh Albert Humphrey dalam perencanaan yang bersifat strategis digunakan untuk mengevaluasi aspek internal yang meliputi kekuatan, dan kelemahan), serta aspek eksternal yang meliputi peluang dan ancaman). Dalam proses analisis SWOT melibatkan penentuan tujuan bisnis dan mengidentifikasi faktor internal dan eksternal yang mendukung dan yang tidak dalam mencapai tujuan tersebut (Humphrey, 2005).

Matriks SWOT berikut adalah hasil identifikasi pendahuluan yang kami lakukan, dan telah dikonfirmasi oleh Mitra UMKM kami.

Tabel 1. Matriks SWOT CV. Panca Boga Langgeng

\section{Strengths (Kekuatan)}

- Sudah berbentuk CV

- Mempunyai pengalaman dan keahlian dalam pembuatan produk bakso/bakwan Weakness (Kelemahan)

- Kapasitas produksi rendah

- Jangkauan pemasaran terbatas

- Pemahaman Pengurusan Ijin Usaha Kurang

- Belum memiliki beberapa legalitas seperti pendaftaran merek, BPOM, PIRT, dan sertifikat halal

\section{Opportunities (Peluang)}

- Mudah mendapatkan tenaga kerja yang berasal dari penduduk sekitar

- Relatif mudah mendapatkan bantuan pinjaman modal karena status perusahaan yang sudah berbentuk CV

- Media pemasaran yang beragam (konvensional dan online)

- Adanya darma perguruan tinggi dibidang pengabdian masyarakat yang dapat membantu pemberdayaan UMKM

\section{Treats (Ancaman)}

- Banyak kompetitor, baik pemain lama, maupun pendatang baru

- Banyak produk subtitusi

- Regulasi yang berlaku untuk industri berbasis makanan

\section{SOLUSI DAN TARGET}

Sistem kerja metode SWOT dalam merumuskan solusi strategis dituangkan dalam matriks. Secara kualitatif, askep internal dan ekternal dijadikan dasar dalam penetapan strategi atau upaya yang dapat dilakukan, agar tujuan bisnis dapat dicapai (Gürel \& Tat, 2017). Berikut adalah solusi strategis yang dapat ditawarkan bagi UKM Mitra : 
Tabel 2. Penetapan Strategi berdasarkan SWOT

\begin{tabular}{|c|c|c|}
\hline OT/SW & $\begin{array}{ll}\text { Strengths (Kekuatan) } & \\
\text { - } & \text { Sudah berbentuk CV } \\
\text { - } & \text { Mempunyai pengalaman } \\
& \text { dan keahlian dalam } \\
& \text { pembuatan r produk } \\
& \text { bakso/bakwan }\end{array}$ & $\begin{array}{l}\text { Weakness (Kelemahan) } \\
\text { - }\end{array}$ \\
\hline $\begin{array}{ll}\text { Opportunities (Peluang) } \\
\text { - } & \text { Mudah mendapatkan } \\
\text { tenaga kerja yang berasal } \\
\text { dari penduduk sekitar } \\
\text { - Relatif mudah } \\
\text { mendapatkan bantuan } \\
\text { pinjaman modal karena } \\
\text { status perusahaan yang } \\
\text { sudah berbentuk CV } \\
\text { Media pemasaran yang } \\
\text { beragam (konvensional dan } \\
\text { online). } \\
\text { Adanya darma perguruan } \\
\text { tinggi dibidang pengabdian } \\
\text { masyarakat yang dapat } \\
\text { membantu pemberdayaan } \\
\text { UMKM }\end{array}$ & $\begin{array}{l}\text { Srategi SO } \\
\text { SO } 1 \text { : Mengajukan pinjaman } \\
\text { modal untuk menambah mesin } \\
\text { produksi dan memperbesar } \\
\text { kapasitas produksi. } \\
\text { SO } 2 \text { : Mempelajari pengurusan } \\
\text { ijin edar BPOM }\end{array}$ & $\begin{array}{l}\text { Strategi WO } \\
\text { WO } 1 \text { : Memperbanyak } \\
\text { kapasitas produksi } \\
\text { WO } 2 \text { : Memperluas jangkauan } \\
\text { pemasaran } \\
\text { WO } 3: \text { Mengurus pendaftaran } \\
\text { merek, ijin BPOM, PIRT } \\
\text { melalui bantuan Perguruan } \\
\text { Tinggi }\end{array}$ \\
\hline 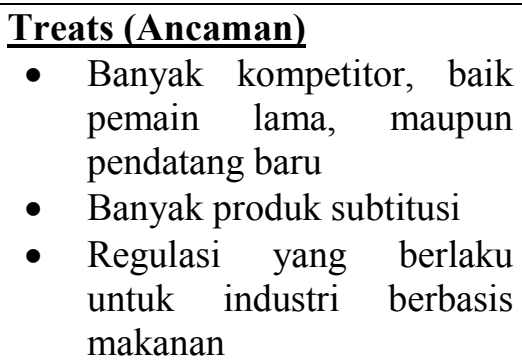 & $\begin{array}{l}\text { Strategi ST } \\
\text { ST } 1 \text { : Terus berinovasi dengan } \\
\text { memperbanyak varian produk } \\
\text { dan kemasan yang menarik }\end{array}$ & $\begin{array}{l}\text { Strategi WT } \\
\text { WT } 1 \text { : Meningkatkan } \\
\text { jangkauan pemasaran yang } \\
\text { lebih luas } \\
\text { WT } 2 \text { : Membuat strategi } \\
\text { pemasaran yang lebih efektif } \\
\text { dan efisien }\end{array}$ \\
\hline
\end{tabular}

Sumber : Data hasil olahan

Dari matriks tersebut, UMKM yang menjadi mitra memiliki alternatif strategi yang disesuaikan dengan batasan aktifitas pengabdian masyarakat serta memperhatikan skala prioritas dan keterbatasan ruang lingkup serta waktu pelaksanaan maka, pendampingan yang dapat diberikan adalah dalam bentuk sebagai berikut :

1 Dengan memperhatikan matriks di atas, maka untuk program abdimas untuk mendukung strategi mitra meliputi ST 1; WT 2; WT 3; WO 1 dan WO 2 maka bentuk kegiatan abdimas yang dilaksanakan adalah melaksanakan Pendampingan pada mitra dalam dalam bentuk sosialisasi untuk memahami bentuk-bentuk peraturan dan perizinan apa yang perlu dimiliki sebagai suatu bidang usaha industri makanan 


\section{Jurnal ABDINUS : Jurnal Pengabdian Nusantara, 3 (1), 2019, 100-110}

Albertus Daru Dewantoro, Alberth, Nathan Nikolaus, dkk

2 Dengan memperhatikan matriks di atas, maka untuk program abdimas untuk mendukung strategi mitra meliputi SO 2; WO 3 maka bentuk kegiatan abdimas yang dilaksanakan adalah melaksanakan pendampingan pada mitra dalam dalam bentuk fasilitasi pengurusan pajak sewa lokasi usaha dan penerbitan NPWP sebagai syarat wajib mengurus ijin usahanya dan memperoleh SIUP serta ijin edar BPOM.

Dari rumusan bentuk program diatas maka target yang ditetapkan dalam abdimas ini adalah sebagai berikut :

1. Mitra pengusaha pangan memahami pentingnya ijin edar bagi peningkatan kapasitas UKM,

2. Mitra memahami alur atau langkah-langkah mengurus ijin edar, serta

3. Mitra memahami tanggungjawab sosial untuk menjamin kualitas dan keamanan pangan dari produk yang dihasilkan

4. Mitra memiliki NPWP sebagai syarat wajib mengurur ijin edar BPOM.

5. Mitra memahami tanggungjawab sebagai warga negara yang baik untuk membayar pajak atas usaha yang dilakukan.

6. Mitra memiliki ijin usahanya dan memperoleh SIUP

7. Mitra mengurus ijin edar BPOM, untuk target ini, abdimas hanya memiliki target agar mitra mendapatkan bukti registrasi pendaftaran ijin edar BPOM melalui fasilitas e-BPOM dikarenakan waktu dan prosesnya sangat situasional.

\section{METODE PELAKSANAAN}

Secara keseluruhan kegiatan abdimas ini akan dilaksanakan mulai tanggal 28 Januari 2019 s.d 13 Juli 2019, atau sekitar 20 minggu sesuai dengan Timeline yang ditetapkan oleh LPPM Universitas Katolik Darma Cendika. Kegiatan pengabdian masyarakat dijadwalkan berdasarkan agenda sebagai berikut :

1. Minggu 1 : Perkenalan dengan UKM Mitra, serta menjelaskan maksud dan tujuan pelaksanaan kegiatan

2. Minggu 2-3 : Melakukan penelitian pendahuluan, menggunakan metode SWOT.

3. Minggu 4 : Melaksanakan FGD (Focus Group Discussion) sebagai sarana konfirmasi hasil temuan dalam proses analisa SWOT.

4. Minggu 5-10 : Implementasi Program Prioritas :

i. Mempelajarai mekanisme pengurusan NPWP, ijin edar BPOM 


\section{Jurnal ABDINUS : Jurnal Pengabdian Nusantara, 3 (1), 2019, 100-110}

Albertus Daru Dewantoro, Alberth, Nathan Nikolaus, dkk

ii. Mensosialisasikan pada UKM MITRA terkait PP No. 28 Tahun 2004 tentang Keamanan, Mutu Dan Gizi Pangan dan UU No. 18 Tahun 2012 tentang Pangan.

iii. Pendampingan UKM Mitra dalam persiapan perijinan ijin edar BPOM

5. Minggu 11-15 : Implementasi program tambahan

i. Membantu/ memfasiltasi pengurusan NPWP.

ii. Membantu/ memfasiltasi pengurusan NPWP Ijin Usaha

iii. Membantu/ memfasiltasi pengurusan dan Ijin Edar BPOM

6. Minggu 16-20 : Penyusunan Laporan dan Output Pengabdian Masyarakat yang meliputi

i. Laporan yang disahkan oleh LPPM

ii. Pemberitaan di Media (Url)

iii. Penerbitan Jurnal Pengabdian pada masyarakat.

\section{HASIL DAN LUARAN}

Dalam analsis SWOT permasalahan yang dialami mitra adalah belum memahami bentuk-bentuk perizinan apa yang perlu dimiliki sebagai suatu bidang usaha industri makanan, dan belum memahami memahami syarat-syarat apa saja yang harus dipersiapkan untuk mengurus perizinan. Maka kebermaknaan kegiatan pengabdian masyarakat kami adalah bagaimana membantu UKM Mitra dalam mengatasi permasalahan yang dihadapi dengan memanfaatkan pengetahuan yang diperoleh dalam proses pendidikan dan pengajaran, serta bagaimana kami mampu menggali informasi baru yang bermanfaat bagi pemberdayaan UKM Mitra.

Industri Rumah Tangga Pangan, yang selanjutnya disebut IRTP adalah perusahaan pangan yang memiliki tempat usaha di tempat tinggal dengan peralatan pengolahan pangan manual hingga semi otomatis, sedangkan Pangan Produksi IRTP adalah pangan olahan hasil produksi Industri Rumah Tangga Pangan yang diedarkan dalam kemasan eceran dan berlabel. IRTP harus memahami Cara Produksi Pangan yang Baik untuk Industri Rumah Tangga, yang selanjutnya disingkat CPPB-IRT adalah cara produksi yang memperhatikan aspek keamanan pangan bagi IRTP untuk memproduksi pangan agar bermutu, aman dan layak dikonsumsi (Komala, Widajanti, \& Pangestuti, 2017).

Pemilik UKM memiliki keinginan kuat untuk meningkatkan kapasitas UMKM dengan meningkatkan volume penjualan. Melalui analisis SWOT yang telah dilakukan mita memahami kekuatan, kelemahan, ancaman dan potensi dari mitra. Untuk meningkatkan 


\section{Jurnal ABDINUS : Jurnal Pengabdian Nusantara, 3 (1), 2019, 100-110}

Albertus Daru Dewantoro, Alberth, Nathan Nikolaus, dkk

penjualan maka produk yang dihasilkan tidak dijual melalui cara yang selama ini dilakukan yaitu melalui penjualan ke tetangga dan rekan, penjualan harus bisa masuk di pasar ritail. Hal tersebut menjadi tidak dapat dilakukan karena terhambat dengan legalitas produk yang merupakan salah satu jaminan keamanan dan kualitas makanan. Agar produk dapat beredar di pasar yang lebih luas para pengusaha makanan berkewajiban untuk mendaftarakan produk pangan olahannya yang diatur dalam PP No. 28 Tahun 2004 tentang Keamanan, Mutu Dan Gizi Pangan dan UU No. 18 Tahun 2012 tentang Pangan (Sekretariat Negara Indonesia, 2004, 2012). Ada beberapa faktor yang menyebabkan banyak pengusaha makanan masih belum memiliki nomor izin edar dari BPOM.

Hasil program abdimas mahasiswa UKDC meliputi hal-hal sebagai berikut, melalui program sosialisasi, mitra pengusaha pangan memahami pentingnya ijin edar bagi peningkatan kapasitas UKM, dan memahami alur atau langkah-langkah mengurus ijin edar, serta UKM memahami tanggungjawab sosial untuk menjamin kualitas dan keamanan pangan dari produk yang dihasilkan. Melalui program fasiltasi, membantu pengusaha mengurus pajak sewa lokasi usaha dan penerbitan NPWP sebagai syarat wajib mengurur ijin edar BPOM. Dengan memiliki NPWP, pengusaha juga memahami tanggungjawab sebagai warga negara yang baik untuk membayar pajak atas usaha yang dilakukan. Dalam pengurusan NPWP pengusaha wajib mendaftarkan ijin usahanya, melalui program fasilitasi ini pengusaha telah mendaftarkan ijin usahanya dan memperoleh SIUP dengan nomor 503 / 3580.A / 436.7.17 / 2019 tertanggal 15 April 2019. Program fasiltasi yang terakhir adalah mengurus ijin edar BPOM, dan kelompok 21 bersama mitra pengusaha UKM telah mendaftarkan ijin edar BPOM melalui fasilitas e-BPOM dengan nomor registrasi : 2019040050.

\section{SIMPULAN}

Abdimas bagi dosen dan mahasiswa adalah darma yang penting untuk dilakukan selain darma pendidikan - pengajaran dan penelitian. Kegiatan abdimas yang dilakukan harus memiliki kebermaknaan bagi mitra. Mitra sebagai subjek pendampingan harus merasakan dampak langsung dari kegiatan abdimas tersebut, yaitu dengan meningkatnya kapsitas mitra. Harapan pemilik dari UKM Mitra abdimas kami adalah, agar supaya kegiatan abdimas yang dilakukan oleh civitas akademika UKDC dapat berjalan berkesinambungan, dampaknya dapat diperluas dengan mendampingi UKM-UKM lainnya agar memiliki pengalaman yang sama dengan dirinya. Dengan memiliki legalitas usaha kesempatan untuk mampu bersaing dan 
Jurnal ABDINUS : Jurnal Pengabdian Nusantara, 3 (1), 2019, 100-110

Albertus Daru Dewantoro, Alberth, Nathan Nikolaus, dkk

meningkatkan kapsitas penjualan lebih besar sehingga dapat membantu negara dalam pengatan perekonomian bangsa.

\section{DAFTAR RUJUKAN}

Departemen Kesehatan, R. I. (2009). Undang-Undang Republik Indonesia nomor 36 tahun 2009 tentang kesehatan. Jakarta: Kementrian Kesehatan RI.

Gürel, E., \& Tat, M. (2017). SWOT Analysis: A Theoretical Review. Journal of International Social Research, 10(51).

Humphrey, A. S. (2005). SWOT analysis. Long Range Planning, 30, 46-52.

Komala, I. S., Widajanti, L., \& Pangestuti, D. R. (2017). Cara Produksi Pangan Yang Baik Untuk Industri Rumah Tangga (Cppb-Irt) Perusahaan Tahu Putih “Sl” Kabupaten Semarang Tahun 2017. Jurnal Kesehatan Masyarakat (e-Journal), 5(4), 690-697. Sekretariat Negara Indonesia. (2004). Peraturan Pemerintah No. 28 Tahun 2004 tentang Keamanan Mutu dan Gizi Pangan. Sekretariat Negara. Jakarta.

Sekretariat Negara Indonesia. (2012). UU No. 18 Tahun 2012 tentang Pangan. Sekretariat Negara. Jakarta.

\section{Lampiran 1}

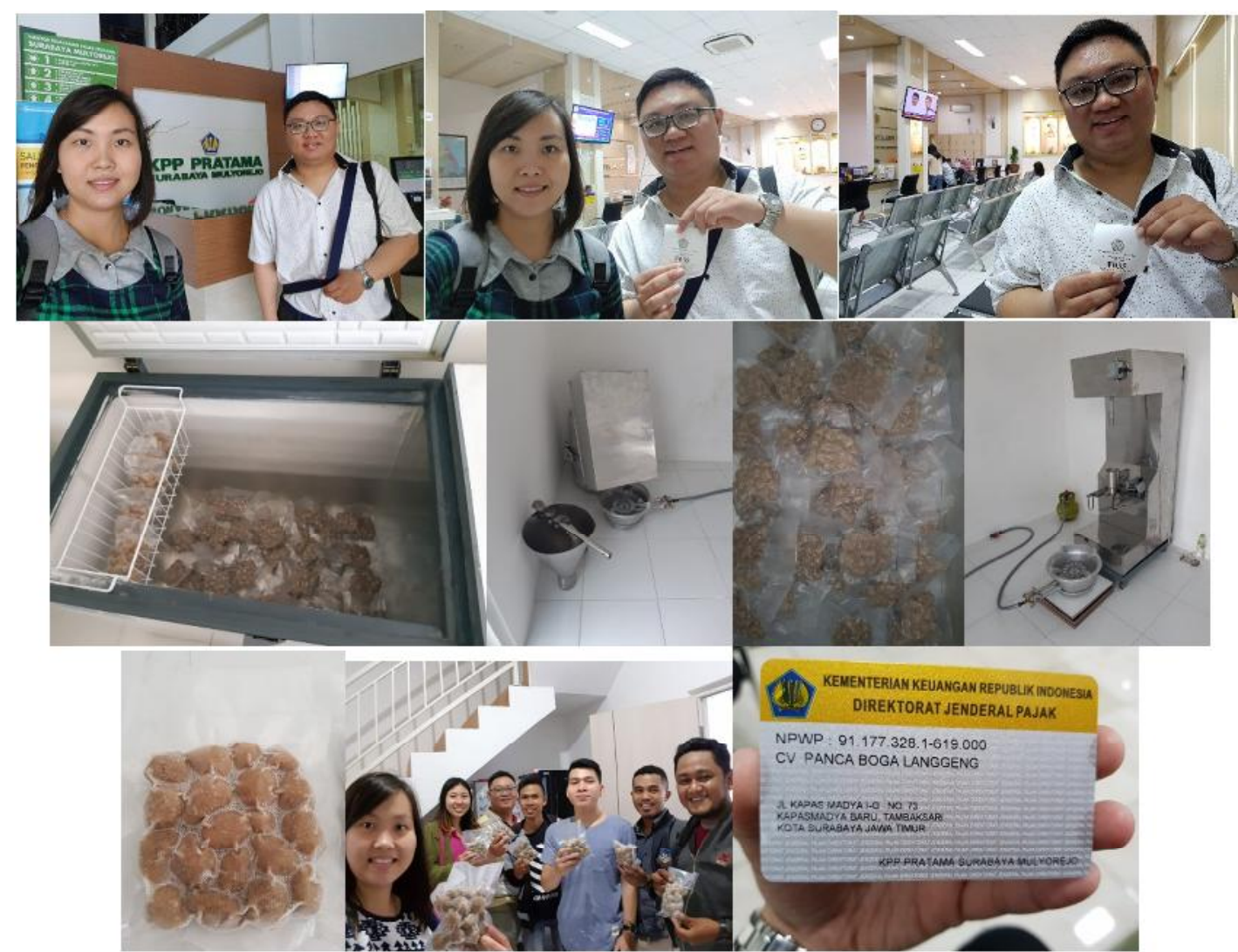


Jurnal ABDINUS : Jurnal Pengabdian Nusantara, 3 (1), 2019, 100-110

Albertus Daru Dewantoro, Alberth, Nathan Nikolaus, dkk

Terima Kasih Telah Mendaftar di e-BPOM.

Data registrasi Anda telah kami terima.

Silahkan menunggu email konfirmasi selanjutnya setelah Data Registrasi

Perusahaan Anda Divalidasi.

Berikut informasi pendaftaran Anda :

Ditujukan Ke : Balai Besar POM Surabaya

No. Registrasi : 2019040050

Username : samuelri

Nama Perusahaan : CV. panca boga langgeng

NPWP : $\quad 91.177 .328 .1-619.000$

No. API/APIU :

Jenis Usaha : Industri Kecil Menengah

Nama Jenis Usaha : Produsen pengolahan hasil ternak dan pengecer hasil

olahannya

No. Ijin Usaha : $\quad 503$ / 3580.A / 436.7.17 / 2019

Tgl. Ijin Usaha : 15-04-2019

Alamat Perusahaan : Jl. kapas madya I G / 73

Propinsi : Prov. Jawa Timur

Kota / Kabupaten : Kota Surabaya

Kode Pos: 60137

Email Perusahaan : pancabogalanggeng@gmail.com

No. Telepon : 081333331841

No. Fax :

Alamat Gudang :

No. Telepon Gudang : 
Jurnal ABDINUS : Jurnal Pengabdian Nusantara, 3 (1), 2019, 100-110

Albertus Daru Dewantoro, Alberth, Nathan Nikolaus, dkk

\section{Lampiran 2. Abdimas Dimuat dalam Media Massa}

Link/ URL : https://radarsurabaya.jawapos.com/read/2019/06/22/142616/abdimas-ukdcbantu-kemandirian-ekonomi-masyarakat-melalui-umkm
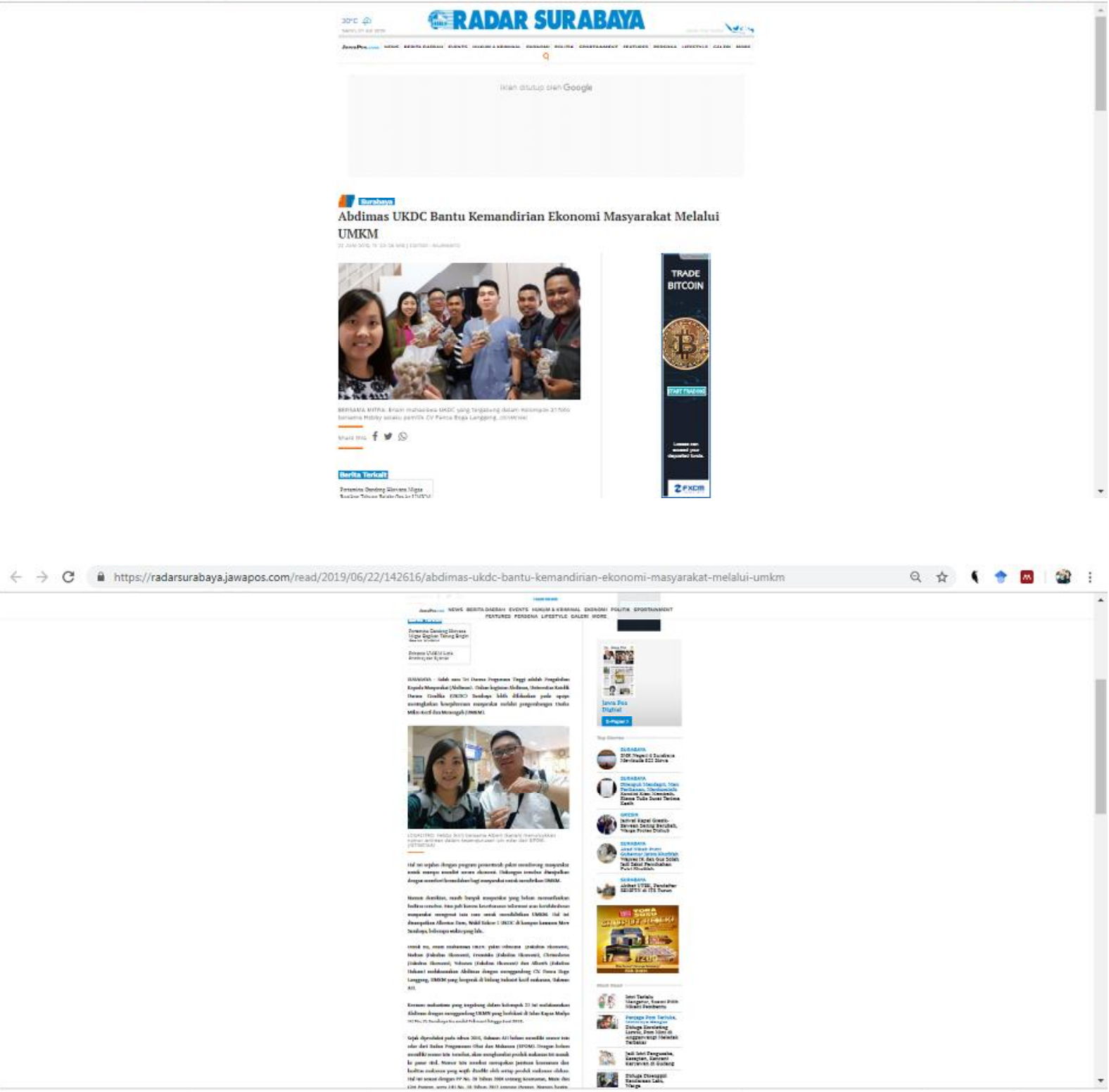